\title{
Effects of Sex and Gender on Adaptation to Space: Neurosensory Systems
}

\author{
Millard F. Reschke, PhD, Helen S. Cohen, EdD, ${ }^{2}$ Jody M. Cerisano, BS, ${ }^{3}$ Janine A. Clayton, PhD, ${ }^{4}$ \\ Ronita Cromwell, $\mathrm{PhD},{ }^{5}$ Richard W. Danielson, $\mathrm{PhD},{ }^{2}$ Emma Y. Hwang, PhD, ${ }^{3}$ \\ Candace Tingen, $\mathrm{PhD},{ }^{6}$ John R. Allen, $\mathrm{PhD},{ }^{7}$ and David L. Tomko, $\mathrm{PhD}^{8}$
}

\begin{abstract}
Sex and gender differences have long been a research topic of interest, yet few studies have explored the specific differences in neurological responses between men and women during and after spaceflight. Knowledge in this field is limited due to the significant disproportion of sexes enrolled in the astronaut corps. Research indicates that general neurological and sensory differences exist between the sexes, such as those in laterality of amygdala activity, sensitivity and discrimination in vision processing, and neuronal cell death (apoptosis) pathways. In spaceflight, sex differences may include a higher incidence of entry and space motion sickness and of post-flight vestibular instability in female as opposed to male astronauts who flew on both short- and longduration missions. Hearing and auditory function in crewmembers shows the expected hearing threshold differences between men and women, in which female astronauts exhibit better hearing thresholds. Longitudinal observations of hearing thresholds for crewmembers yield normal age-related decrements; however, no evidence of sex-related differences from spaceflight has been observed. The impact of sex and gender differences should be studied by making spaceflight accessible and flying more women into space. Only in this way will we know if increasingly longer-duration missions cause significantly different neurophysiological responses in men and women.
\end{abstract}

$\mathbf{T}$ HE ROLES OF SEX AND GENDER in spaceflight are not well understood because the astronaut corps has been, and continues to be, mostly male despite the importance of having both sexes equally represented in most human research. When discussing sex and gender differences, we are concerned with all phases of spaceflight and not simply the differences that may be directly related to the microgravity segment of flight. There are neurophysiological, sensorimotor, and sensory differences between men and women related to spaceflight. We see these differences most clearly in neural anatomy and functional responses; however, the impact of these differences is unclear.

\section{General Neurological Differences}

The brain exhibits extensive sex differences in gross anatomy, differentiation and development of neurons, neurochem- ical pathways, and responses to stress or other environmental cues. ${ }^{1}$ Also, many central nervous system-related disorders show sex differences in their incidence and nature, including, but not limited to Alzheimer's disease, post-traumatic stress disorder, anxiety disorders, schizophrenia, stroke, multiple sclerosis, autism, addiction, fibromyalgia, attention deficit disorder, irritable bowel syndrome, Tourette's syndrome, and eating disorders. $^{2-4}$

\section{Specific Neurological and Sensory Differences \\ Memory processing}

Studies consistently indicate a preferential involvement of the left amygdala in memory for emotional material (generally visual images) in women, but a preferential involvement of the right amygdala in memory for the same material in

\footnotetext{
${ }^{1}$ Department of Neuroscience, NASA Johnson Space Center, Houston, Texas.

${ }^{2}$ Department of Otolaryngology - Head and Neck Surgery, Baylor College of Medicine, Houston, Texas.

${ }^{3}$ Wyle Science, Technology and Engineering Group, Houston, Texas.

${ }^{4}$ Office of Research on Women's Health and ${ }^{6}$ National Institute on Minority Health and Health Disparities, National Institutes of Health, Bethesda, Maryland.

${ }^{5}$ Universities Space Research Association, Houston, Texas.

${ }^{7}$ Human Exploration and Operations Mission Directorate and ${ }^{8}$ Space Life and Physical Sciences Research Division, National Aeronautics and Space Administration (NASA) Headquarters, Washington, DC.
} 
males. ${ }^{5-7}$ This laterality, "women left, men right," mirrors what is seen at rest, indicating that the response to emotional stimulation stems from a baseline that is already differentially "tilted" between the sexes.

\section{Neuronal cell death}

Neuronal cell death pathways differ between men and women. Female neurons more often die through classical, caspase-dependent apoptosis, while male cells die more often through caspase-independent, apoptosis initiating factor-mediated cell death. This finding could potentially be important in developing treatment for neurodegenerative disorders or injuries following stroke. ${ }^{8}$

\section{Opioid receptor binding}

Several brain regions show significantly different levels of opioid receptor binding in men versus women, including the amygdala and thalamus. These differences can lead to sex differences in response to pain analgesics. ${ }^{9}$

\section{Vision processing}

Men have significantly greater sensitivity for fine detail and for rapidly moving stimuli, while women exhibit better color discrimination, in part because many males suffer from color blindness, an X-chromosome related genetically inherited disorder. ${ }^{10,11}$

\section{Somatosensation}

Relatively little information is available on sex differences associated with tactile sensation, but some differences are known. On average, women are more sensitive than men, over the entire body, to touch and pressure. Women appear to be more sensitive to temperature differences while men score better than females on a variety of haptic tasks (object or position recognition involving touch and proprioception).

Reporting of pain and pain sensation is rife with many biases (social, gender, ethnicity, culture, etc.), but on average, women do appear to show a greater sensitivity to pain than men-probably due to biological mechanisms, as well as psychological and psychosocial factors. ${ }^{12}$

\section{Vestibular system}

The vestibular system is notoriously difficult to assess. Relevant research includes anatomy, central physiology, and functions affected by vestibular input including postural responses, spatial orientation, responses to intense motion stimuli, and the occurrence of disease.

Gross anatomy. Women have fewer total myelinated axons in the vestibular nerve than men, which may help explain the female bias (that has been verified via epidemiological studies ${ }^{16,17}$ ) of developing many vestibular disorders, such as vertigo. ${ }^{13}$ In men, the otoliths, utricle, saccule, and superior semicircular canals are significantly larger than in women. $^{14}$

Vestibular nucleus and hormones. In rats, some evidence suggests that the estrus (menstrual) cycle may influence the medial vestibular nucleus synaptic transmission and plastic- ity, with the levels of circulating $17 \beta$ estradiol being the main factor in these differences. ${ }^{15}$

Spatial task performance. Sex differences have been found in circular vection (orientation within a spinning environment), field dependence (perceiving orientation based only on visual cues), perception of veridical vertical with body tilt (correctly identifying the true vertical to the ground when the body is tilted), and perception of the morphological horizon. ${ }^{18,19}$ These differences have been partially assigned to biological differences in the vestibular system, including the difference in otolith size, but some evidence suggests that cognitive training regarding attention to cues can decrease these sex differences. ${ }^{20}$

Motion sickness-laboratory testing. A commonly held belief is that females are more susceptible to motion sickness than males. Both social and research design have probably contributed to this bias. Research conducted in the NASA Johnson Space Center's Neurosciences Laboratory has subjected over 200 subjects to a variety of motion sickness tests (coriolis sickness susceptibility [CSSI], sudden stop, offvertical rotation, parabolic flight, etc.). No difference was found in susceptibility between men and women nor did testing during any phase of the menstrual cycle for females have an effect. Responses to particular tests were variable. For example, some individuals became nauseous during a CSSI test but not during the off-vertical axis rotation test. ${ }^{21,22}$

Motion sickness: spaceflight. The incidence of motion sickness obtained from post-flight debriefs of long-duration International Space Station, or "space station," (32 male, 10 female) and short-duration Space Shuttle (564 male, 100 female) astronauts show that, on average, female crewmembers that flew on both the space station and shuttle reported both space motion sickness and entry motion sickness (EMS) symptoms more frequently than male crewmembers (these data were mined from the NASA Lifetime Surveillance of Astronaut Health [LSAH] database). The one exception is that men who were crew members on the space station reported a higher incidence of EMS than women after returning from a long-duration spaceflight.

Postural ataxia: spaceflight. On average, female crewmembers who flew on both the space station and space shuttle reported post-flight vestibular instability symptoms (feeling abnormally heavy, clumsiness, vertigo, persisting sensation after-effects, or having difficulty walking a straight line) more frequently than male crewmembers (these data were also mined from the LSAH database). All responses were subjective and were reported to a flight surgeon as part of a standard post-flight medical debrief. The debrief did not always specify the symptoms. In a study of computerized dynamic posturography before and after long-duration bed rest, analyses of sensory organization test scores suggest no differences between men and women. ${ }^{23}$

\section{Hearing/auditory function}

Numerous epidemiological studies have been conducted to compare differences in hearing sensitivity among men and women, confirming that hearing sensitivity declines with age, 
even in populations screened for a history of noise exposure. $^{24-26}$ These studies have also shown that hearing sensitivity (when reported by conventional pure-tone audiometry) declines faster in men than in women at most ages and in most frequencies tested. ${ }^{27}$ The most recent National Health and Nutrition Examination Survey ${ }^{28}$ revealed that the odds of such hearing loss were 5.5-fold higher in men than in women. Even when studies carefully screen for ear disease and noise exposures, however, hearing levels and longitudinal patterns of hearing change are highly variable. This variability has been attributed to smoking, genetic factors, and cardiovascular risks. ${ }^{29}$ Hearing sensitivity is particularly vulnerable to hazardous noise exposures (e.g., in industrial, military, and recreational environments), but sex differences in age-associated hearing loss occur even among populations with relatively low-noise occupations and with no evidence of noise-induced hearing loss. ${ }^{25}$

In addition to pure-tone audiometry, distortion product otoacoustic emissions (DPOAEs) have also been used to assess peripheral hearing status. DPOAEs are believed to reveal subtle cochlear changes that may be overlooked by audiometry. ${ }^{30,31}$ Studies show that aging males experience greater decreases in DPOAEs amplitudes compared to aging females. This decrease in DPOAEs is often proportional to the degree of hearing loss. ${ }^{31,32}$

NASA conducts a unique hearing-monitoring program, in which crew members undergo audiometric testing at least once per year during their active astronaut career (and even more frequently when assigned to space missions). Later, when participating in NASA's LSAH program, former astronauts may continue to have their hearing tested for the rest of their lives. This database offers the opportunity to compare longitudinal differences in hearing sensitivity seen in male and female astronauts over as much as a 5-decade span of life (Fig. 1).

When comparing high-frequency hearing sensitivity, the LSAH database's female population has better hearing thresholds than men at every epoch of life, starting in their mid-30s, approximately the age when most astronauts begin their careers. Female astronauts show no significant differences in hearing thresholds between ears except in those older than 55 (though the sample size for this population is rather small at that age), when the left ear thresholds are slightly better than those in the right ear. Male astronauts show greater hearing loss in the left ear than in the right ear at every age; this finding is consistent with many demographic studies, particularly those in which right-handed subjects have shot shoulder-fired weapons (exposing the left ear to most of the blast wave from the weapon's muzzle). The vocational and avocational activities of many astronauts, military and nonmilitary, often include such firearms. An important finding from this database (unpublished data) is that although males and females show the expected age-related differences in hearing loss, spaceflight does not seem to affect men and women differently.

\section{The Impact of Sex and Gender on Neurological, Sensory, and Sensorimotor Function Associated with Spaceflight}

The impact of sex and gender on neurophysiological changes observed both during and after flight is unknown. Several questions can and should be asked when we address this issue. For example, are preexisting differences minimized or magnified by spaceflight? Are all current countermeasures equally effective for both sexes? Is there an underlying benefit to being either a man or woman associated with spaceflight, or are there inherent risks associated with sex differences?

To make spaceflight accessible to everyone with the lowest possible risk we must define appropriate risk scenarios that are empirical and can be approached as testable hypotheses. As we continue to explore the cosmos, the answers to questions about sex and gender differences will become essential. To answer these important questions, more women should be flown into space and more crew members, especially women, should be strongly encouraged to participate in research designed to address the sex and gender question. Only with a commitment by crew members, supported by a commitment from NASA management, will we will learn if men and women have significantly different neurophysiological responses to increasingly longer-duration spaceflights. Without the necessary data, appropriate countermeasures for both sexes cannot be developed.

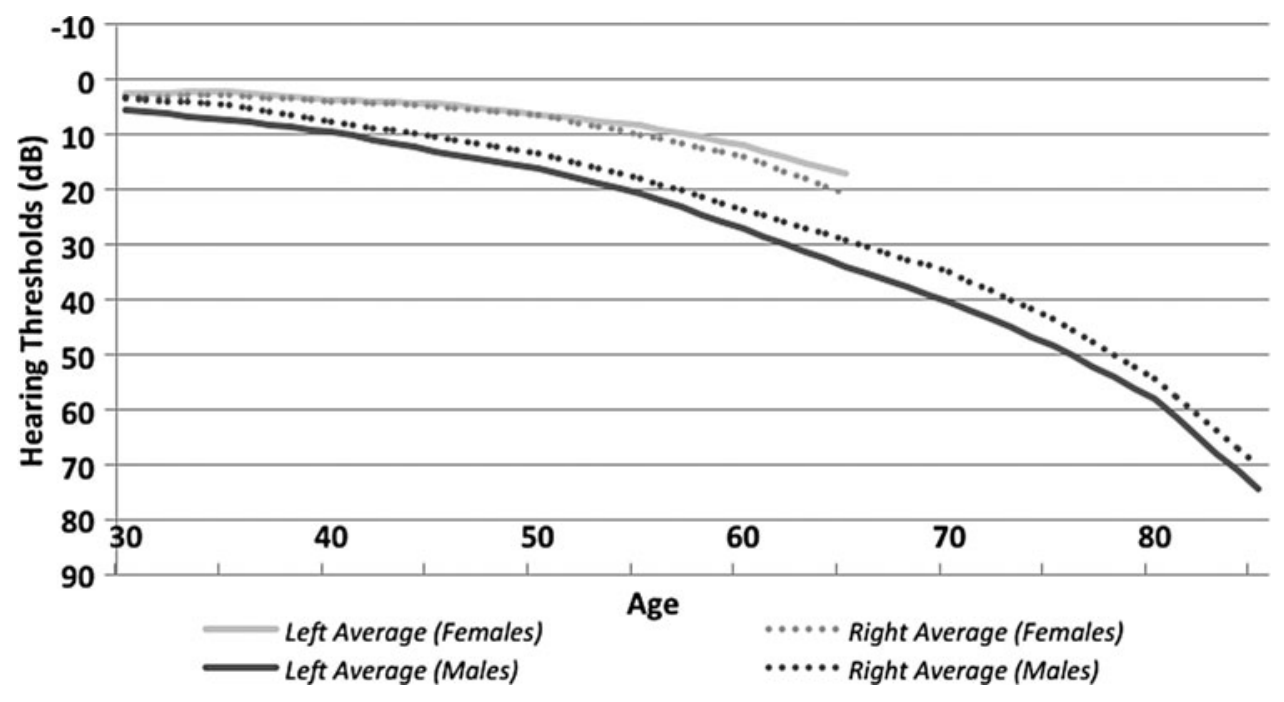

FIG. 1. Hearing trends of male versus female astronauts, by age, for averaging audiometric thresholds at 2k, 3k, and 4k Hertz. 


\section{Author Disclosure Statement}

No competing financial interests exist.

\section{References}

1. Cahill L. Why sex matters for neuroscience. Nat Rev Neurosci 2006;7:477-484.

2. Shors TJ. Opposite effects of stressful experience on memory formation in males versus females. Dialogues Clin Neurosci 2002;4:139-147.

3. Klein LC, Corwin EJ.Seeing the unexpected: how sex differences in stress responses may provide a new perspective on the manifestation of psychiatric disorders. Curr Psychiatry Rep 2006;4:441-448.

4. Hines M. Brain gender. New York: Oxford University Press, 2004.

5. Cahill L, Haier RJ, White NS, et al. Sex-related difference in amygdala activity during emotionally influenced memory storage. Neurobiol Learn Mem 2001;75:1-9.

6. Cahill L, Uncapher M, Kilpatrick L, Alkire MT, Turner J. Sex-related hemispheric lateralization of amygdala function in emotionally influenced memory: An FMRI investigation. Learn Mem 2004;11:261-266.

7. Canli T, Desmond JE, Zhao Z, Gabrieli JD. Sex differences in the neural basis of emotional memories. Proc Natl Acad Sci U S A 2002;99:10789-10794.

8. Lang JT, McCullough LD. Pathways to ischemic neuronal cell death: are sex differences relevant? J Transl Med 2008;6:33.

9. Zubieta JK, Dannals RF, Frost JJ. Gender and age influences on human brain mu-opioid receptor binding measured by PET. Am J Psychiatry 1999;156:842-848.

10. Abramov I, Gordon J, Feldman O, Chavarga A. Sex and vision II: color appearance of monochromatic lights. Biol Sex Differ 2012;3:21.

11. Abramov I, Gordon J, Feldman O, Chavarga A. Sex and vision I: Spatio-temporal resolution. Biol Sex Differ 2012;3:20.

12. Schroeder JA. Sex and gender in sensation and perception. In: Chrisler JC, McCreary, DR, eds. Handbook of gender research in psychology. New York: Springer Science+ Business Media, 2006:235-257.

13. Moriyama H, Itoh M, Shimada K, Otsuka N. Morphometric analysis of fibers of the human vestibular nerve: sex differences. Eur Arch Otorhinolaryngol 2007;264:471-475.

14. Sato H, Sando I, Takahashi H. Computer-aided threedimensional measurement of the human vestibular apparatus. Otolaryngol Head Neck Surg 1992;107:405-409.

15. Grassi S, Frondaroli A, Scarduzio M, et al. Influence of sex and estrous cycle on synaptic responses of the medial vestibular nuclei in rats: role of circulating 17 beta-estradiol. Brain Res Bull 2012;87:319-327.

16. Neuhauser HK, von Brevern M, Radtke A, et al. Epidemiology of vestibular vertigo: a neurotologic survey of the general population. Neurology 2005;65:898-904.

17. von Brevern M, Radtke A, Lezius F, et al. Epidemiology of benign paroxysmal positional vertigo: a population based study. J Neurol Neurosurg Psychiatry 2007;78:710-715.

18. Darlington CL, Smith PF. Further evidence for gender differences in circularvection. J Vestib Res 1998;8:151-153.
19. Tremblay L, Elliott D. Sex differences in judging selforientation: the morphological horizon and body pitch. BMC Neurosci 2007;8:6.

20. Tremblay L, Elliott D, Starkes JL. Gender differences in perception of self-orientation: software or hardware? Perception 2004;33:329-337.

21. Reschke MF. Statistical prediction of space motion sickness. In: GH Crampton, ed. Motion and space sickness. Boca Raton, FL: CRC Press, Inc., 1990:263-316.

22. Harm DL. Physiology of motion sickness symptoms. In: GH Crampton, ed. Motion and space sickness. Boca Raton, FL: CRC Press, Inc., 1990:153-177.

23. Esteves JT, Taylor LC, Vanya RD, Dean SL, Wood SJ Postural control decrements using long duration bed rest as a spaceflight analog. Poster presentation at 18th IAA Humans in Space Symposium, April 11-15, 2011, Houston, TX.

24. Albera R, Lacilla M, Piumetto E, Canale A. Noise-induced hearing loss evolution: influence of age and exposure to noise. Eur Arch Otorhinolaryngol 2010;267:665-671.

25. Pearson JD, Morrell CH, Gordon-Salant S, et al. Gender differences in a longitudinal study of age-associated hearing loss. J Acoust Soc Am 1995;97:1196-1205.

26. American National Standards Institute. Determination of occupational noise exposure and estimation of noiseinduced hearing impairment (with Erratum). Standard S 3.441996. New York: Acoustical Society of America, 1996 (rev 2006).

27. Rosenhall U. The influence of ageing on noise-induced hearing loss. Noise Health 2003;5:47-53.

28. Agrawal Y, Platz EA, Niparko JK. Prevalence of hearing loss and differences by demographic characteristics among US adults: Data from the National Health and Nutrition Examination Survey, 1999-2004. Arch Intern Med 2008; 168:1522-1530.

29. Cruickshanks KJ, Klein R, Klein BE, Wiley TL, Nondahl DM, Tweed TS. Cigarette smoking and hearing loss: The epidemiology of hearing loss study. JAMA 1998;279:17151719.

30. Attias J, Horovitz G, El-Hatib N, Nageris B. Detection and clinical diagnosis of noise-induced hearing loss by otoacoustic emissions. Noise Health 2001;3:19-31.

31. Cilento BW, Norton SJ, Gates GA. The effects of aging and hearing loss on distortion product otoacoustic emissions. Otolaryngol Head Neck Surg 2003;129:382-389.

32. Korres GS, Balatsouras DG, Tzagaroulakis A, Kandiloros D, Ferekidou E, Korres S. Distortion product otoacoustic emissions in an industrial setting. Noise Health 2009;11: $103-110$.

Address correspondence to: Millard F. Reschke, PhD

Department of Neuroscience

National Aeronautics and Space Administration Johnson Space Center 2101 NASA Parkway Houston, Texas 77058

E-mail: millard.f.reschke@nasa.gov 